\title{
Correction to: Frequency and characteristics of contralateral breast abnormalities following recall at screening mammography
}

\author{
Joost R. C. Lameijer ${ }^{1}$ (1) - Angela MP Coolen ${ }^{2}$ - Adri C. Voogd ${ }^{3,4,5} \cdot$ Luc J. Strobbe $^{6} \cdot$ Marieke W. J. Louwman $^{4}$. \\ Dick Venderink $^{6}$ • Vivian C. Tjan-Heijnen ${ }^{5}$ Lucien E. M. Duijm ${ }^{6,7}$
}

Published online: 25 June 2018

(C) The Author(s) 2018

\section{Correction to: Eur Radiol \\ https://doi.org/10.1007/s00330-018-5370-x}

The original version of this article, published on 17 April 2018, unfortunately contained a mistake. The following correction has therefore been made in the original:

The name of Angela MP Coolen and the affiliations were presented incorrectly. The corrected author list is given above; the corrected affiliations are given below. The original article has been corrected.

Open Access This article is distributed under the terms of the Creative Commons Attribution 4.0 International License (http:// creativecommons.org/licenses/by/4.0/), which permits unrestricted use, distribution, and reproduction in any medium, provided you give appropriate credit to the original author(s) and the source, provide a link to the Creative Commons license, and indicate if changes were made.

The online version of the original article can be found at https://doi.org/ 10.1007/s00330-018-5370-x

Joost R. C. Lameijer

joostlameijer@gmail.com

1 Department of Radiology, Catharina Hospital, Michelangelolaan 2, 5623EJ, Eindhoven, The Netherlands

2 Department of Radiology, Elisabeth-Tweesteden Hospital (ETZ), Hilvarenbeekseweg 60, 5022 GC Tilburg, The Netherlands

3 Department of Epidemiology, Maastricht University, P Debyelaan 1, 6229 HA Maastricht, The Netherlands
4 Department of Research, Netherlands Comprehensive Cancer Organization (IKNL), PO Box 19079, 3501 DB Utrecht, The Netherlands

5 Department of Internal Medicine, Division of Medical Oncology, GROW Maastricht University Medical Centre, PO Box 5800, 6202 AZ Maastricht, The Netherlands

6 Department of Radiology, Canisius Wilhelmina Hospital, Weg door Jonkerbos 100, 6532 SZ Nijmegen, The Netherlands

7 Dutch Expert Centre for Screening, PO Box 6873, 6503 GJ Nijmegen, The Netherlands 